6 - ORIGINAL ARTICLE

EFFECTS OF DRUGS

\title{
The effects of enoxaparin on the liver in experimental pneumoperitoneum model ${ }^{1}$
}

\author{
Turgut Cavusoglu', Kemal Kismet ${ }^{\mathrm{I}}$, Namik Ozcan', Berkay Kucuk ${ }^{\mathrm{III}}$, Aziz Mutlu Barlas ${ }^{\mathrm{IV}}$, Bahadir Osman Bozkirli ${ }^{\mathrm{IV}}$, Pinar \\ Celepliv, Mehmet Senes $^{\text {VI, Serkan Bolat }}{ }^{\text {VII }, \text { Sema Hucumenoglu }}$ VIII
}

DOI: http://dx.doi.org/10.1590/S0102-865020160110000006

\begin{abstract}
IAssociate Professor, Department of General Surgery, Ankara Education and Research Hospital, Turkey. Design of the study, analysis of data, technical procedures.

IIAssociate Professor, Department of Anesthesiology and Reanimation, Ankara Education and Research Hospital, Turkey. Critical revision.

IIIMD, Department of General Surgery, Ankara Education and Research Hospital, Turkey. Technical procedures.

${ }^{\text {IV } M D, ~ G e n e r a l ~ S u r g e o n, ~ D e p a r t m e n t ~ o f ~ G e n e r a l ~ S u r g e r y, ~ A n k a r a ~ E d u c a t i o n ~ a n d ~ R e s e a r c h ~ H o s p i t a l, ~ T u r k e y . ~ C o n c e p t i o n ~ o f ~ t h e ~ s t u d y, ~ i n t e r p r e t a t i o n ~ o f ~}$ data.

${ }^{\mathrm{v}} \mathrm{MD}$, Pathologist, Department of Pathology, Ankara Education and Research Hospital, Turkey. Histopathological examinations.

${ }^{\mathrm{V}}$ Associate Professor, Department of Biochemistry, Ankara Education and Research Hospital, Turkey. Biochemical analyses.

${ }^{\mathrm{VII}} \mathrm{MD}$, Department of Biochemistry, Ankara Education and Research Hospital, Turkey. Biochemical analyses.

VIIIFull Professor, Department of Pathology, Ankara Education and Research Hospital, Turkey. Histopathological examinations.
\end{abstract}

\begin{abstract}
PURPOSE: To investigate the potential protective effects of enoxaparin against the adverse events of carbon dioxide $\left(\mathrm{CO}_{2}\right)$ pneumoperitoneum.

METHODS: Thirty four rats were divided into three groups: Group 1 (sham) underwent insertion of Veress needle into the abdomen and $90 \mathrm{~min}$ of anesthesia with no gas insufflation. The animals in control and enoxaparin groups were subjected to $90 \mathrm{~min}$ of $14 \mathrm{mmHg}$ $\mathrm{CO}_{2}$ pneumoperitoneum. Enoxaparin $(100 \mathrm{u} / \mathrm{kg})$ was administered subcutaneously to the rats in enoxaparin group one hour before the operation. After $90 \mathrm{~min}$ of pneumoperitoneum, the rats were allowed for reperfusion through $60 \mathrm{~min}$. Blood and liver samples were obtained for biochemical and histopathological examination.

RESULTS: Treatment with enoxaparin decreased the histopathological abnormalities when compared with the control group. The highest levels of oxidative stress parameters were found in control group. The use of enoxaparin decreased the levels of all oxidative stress parameters, but the difference between the control and enoxaparin groups was not statistically significant.
\end{abstract}

CONCLUSION: Enoxaparin ameliorated the harmful effects of high pressure $\mathrm{CO}_{2}$ pneumoperitoneum on the liver.

Key words: Laparoscopy. Pneumoperitoneum, Artificial. Carbon Dioxide. Enoxaparin. Liver. Oxidative Stress. Rats. 


\section{Introduction}

Laparoscopic surgery is less damaging to immune functions and has lower rates of systemic inflammation as it is a less invasive method, compared to open abdominal operations. Nonetheless, increased intra-abdominal pressure during pneumoperitoneum and inflation-deflation can lead to splanchnic ischemia-reperfusion and oxidative stress. Hemodynamic changes and the impact of carbon dioxide $\left(\mathrm{CO}_{2}\right)$ may also exacerbate oxidative stress during pneumoperitoneum ${ }^{1}$. With the use of highpressure pneumoperitoneum in laparoscopic surgery, portal venous flow is reduced, which results in physiological changes in hepatic function. These changes in hepatic function during laparoscopic surgery are caused by the duration and level of intra-abdominal pressure $^{2}$. With the development of temporary ischemia of the liver during pneumoperitoneum, liver function deteriorates and there is a decreased local cellular immune response. The interlocking mechanisms causing the deleterious effects of pneumoperitoneum on the liver include the changes in hepatic blood flow, changes in monocyte-phagocyte system activity, and decreased immune system function. Abdominal deflation may further aggravate this process, which then creates a reperfusion model in a previously ischemic liver ${ }^{3}$.

Enoxaparin is one of the most common low molecular weight heparin (LMWH) drugs used to treat many thromboembolic diseases. The safety and efficacy of enoxaparin have been established in a wide range of both arterial and venous thromboembolic conditions. The major anticoagulant effect of the drug is mediated by interaction with antithrombin III, which in turn, inactivates serine protease-like factors IIa (thrombin), IXa and Xa. Thus indirectly, enoxaparin inhibits the conversion of prothrombin to thrombin and the thrombin-mediated conversion of fibrinogen to fibrin is reduced, thereby preventing the formation of clots ${ }^{4}$.

Other than the well-established effects on blood coagulation, studies have evaluated many other activities of LMWH, including anti-inflammatory activity ${ }^{5-11}$. These studies have demonstrated that enoxaparin could be effective for managing many inflammatory disorders including, inflammatory reaction after pediatric cataract surgery ${ }^{5}$, ST-segment elevated myocardial infarction ${ }^{6}$, mast cell-mediated allergic inflammation ${ }^{7}$, allergic asthma ${ }^{8,9}$, and acute colitis ${ }^{11}$. Enoxaparin has also been shown to be effective against fibrosis progression in the rat model of cirrhosis ${ }^{12}, \mathrm{CCL}_{4}$-induced necrosis and apoptosis of the liver ${ }^{13}$, dimethylnitrosamine (DMN)-induced liver fibrosis ${ }^{14}$, radiation- induced liver toxicity ${ }^{15}$, and experimental cholestatic liver injury ${ }^{16}$. In addition, the protective effects of heparin have been shown in an experimental hepatic ischemia-reperfusion model ${ }^{17}$.

Based on these effects of enoxaparin, the present study was conducted to investigate the potential protective effects of enoxaparin against the adverse events of high pressure $\mathrm{CO}_{2}$ pneumoperitoneum. The main outcome was to evaluate the effects of enoxaparin on histopathological changes in liver tissue caused by pneumoperitoneum. The possible effects on biochemical parameters and oxidative status were also assessed.

\section{Methods}

This study was conducted in the Husnu Sakal Experimental and Clinical Practice Center, Ankara, Turkey. The procedures in this experimental study were performed in accordance with the National Guidelines for the Use and Care of Laboratory Animals and the Animal Ethics Committee of Ankara Education and Research Hospital (Ankara, Turkey) granted approval for the study.

The study was carried out on 34 Wistar-Albino female rats, each weighing $250 \pm 25 \mathrm{~g}$. The rats were allowed to adapt to laboratory conditions for 1 week before experimental use. The animals were housed under standard laboratory conditions at a constant temperature $\left(21 \pm 2{ }^{\circ} \mathrm{C}\right)$ and relative humidity of $65-70 \%$ with a 12-hour light-dark cycle. The animals were fed with standard laboratory chow and water ad libitum. No enteral or parenteral antibiotics were administered during the study.

All animals were anesthetized with an intramuscular injection of $50 \mathrm{mg} / \mathrm{kg}$ ketamine hydrochloride (Ketalar ${ }^{\circledR}$, ParkeDavis, Istanbul) and $5 \mathrm{mg} / \mathrm{kg}$ xylazine (Rompun ${ }^{\circledR}$, Bayer, Istanbul). The animals were divided into three groups: Group 1 (sham, n=8) underwent insertion of 7 Gauge Veress needle (Wollex ${ }^{\circledR}$, Greatcare Medical GmbH, Gildenweg, Germany) into the abdomen and 90 min of anesthesia with no gas insufflation, maintaining intraabdominal pressure at $0 \mathrm{mmHg}$. The animals in Group 2 (control, $n=12$ ) and Group 3 (enoxaparin group, $n=14$ ) were subjected to $90 \mathrm{~min}$ of $14 \mathrm{mmHg} \mathrm{CO}$ pneumoperitoneum. Enoxaparin $(100 \mathrm{u} /$ $\mathrm{kg}$ ) was administered subcutaneously to the rats in Group 31 hour before the operation. The pneumoperitoneum was created using an electronic insufflator (Ackermann Instrumente, 15-1711, high performance insufflation system, Germany) through a 7-gauge Veress needle maintaining intra-abdominal pressure at $14 \mathrm{mmHg}$. After $90 \mathrm{~min}$ of pneumoperitoneum, the Veress needles were withdrawn and the abdomens of the rats were desufflated. The rats 
were then allowed free movement for reperfusion through $60 \mathrm{~min}$. At the end of this period, blood and liver samples were obtained for biochemical and histopathological examination.

The histopathological analyses were performed in the Pathology Department of Ankara Education and Research Hospital. For light microscopic analyses, the samples were obtained from the liver and fixed in 10\% neutral buffered formalin solution for 2 days. The tissues were washed in running water and were dehydrated with increasing concentrations of ethanol $(50 \%$, $75 \%, 96 \%, 100 \%$ ). After dehydration, the specimens were put into xylene to obtain transparency and were then infiltrated with and embedded in paraffin. The embedded tissues were cut into 4- $\mu \mathrm{m}$ thick sections using a Leica RM 2125 RT microtome and stained with hematoxylin \& eosin. Histopathological examinations were performed with a light microscope (Olympus BX51TF, Tokyo, Japan) by a pathologist blinded to the study design. Histopathological parameters including sinusoidal congestion, hepatocyte necrosis and liver cell vacuolization were evaluated semi-quantitatively according to the modified Suzuki scoring system $^{18}$. The scoring system of these parameters is given in Table 1 .

TABLE 1 - The histopathological scoring system of the liver tissues.

\begin{tabular}{cccc}
\hline Grade & $\begin{array}{c}\text { Sinusoidal } \\
\text { Congestion }\end{array}$ & Vacuolization & Necrosis \\
\hline $\mathbf{0}$ & No & No & No \\
$\mathbf{1}$ & Mild & Mild & Simple cell necrosis \\
$\mathbf{2}$ & Moderate & Moderate & $0-30 \%$ \\
$\mathbf{3}$ & Severe & Severe & $30-60 \%$ \\
$\mathbf{4}$ & Very severe & Very severe & More than $60 \%$ \\
\hline
\end{tabular}

Serum alanine aminotransferase (ALT), aspartate aminotransferase (AST), and alkaline phosphatase (ALP) measurements were performed with a clinical chemistry analyzer Beckman Coulter 5800 using Beckman Coulter commercial kits.

The evaluation of oxidative stress parameters was performed in the Biochemistry Department of Ankara Education and Research Hospital. Tissues were stored at $-80^{\circ} \mathrm{C}$ until the assays. Tissue malondialdehyde (MDA), advanced oxidation protein products (AOPP) levels and tissue fluorescent oxidation products (TFOP) were measured.

MDA levels were calculated using the fluorometric method, as described by Wasowicz et al. ${ }^{19}$ After the reaction of thiobarbituric acid (TBA) with MDA, the reaction product was extracted in butanol and was measured spectrofluorometrically at wavelengths of $525 \mathrm{~nm}$ for excitation and $547 \mathrm{~nm}$ for emission. 0-5 $\mu \mathrm{mol} / \mathrm{L} 1,1$ ',3,3'-tetraethoxypropane solution was used as standard. For the measurement of tissue MDA levels; $50 \mu \mathrm{L}$ of homogenate was added and introduced into $10 \mathrm{~mL}$ glass tubes containing $1 \mathrm{~mL}$ of distilled water. After the addition of $1 \mathrm{~mL}$ of the solution containing $29 \mathrm{mmol} / \mathrm{L}$ TBA in acetic acid and mixing, the samples were placed in a water bath and heated for 1 $\mathrm{h}$ at $95-100^{\circ} \mathrm{C}$. The samples were then cooled, $25 \mu \mathrm{L}$ of $5 \mathrm{~mol} / \mathrm{L}$ hydrochloric acid (HCL) was added and the reaction mixture was extracted by agitation for $5 \mathrm{~min}$ with $3.5 \mathrm{~mL}$ n-butanol. After separation of the butanol phase by centrifugation at 1500 $\mathrm{x} \mathrm{g}$ for $10 \mathrm{~min}$, the fluorescence of the butanol extract was measured with a fluorometer (HITACHI F-2500) at wave-lengths of $525 \mathrm{~nm}$ for excitation and $547 \mathrm{~nm}$ for emission. $0-5 \mu \mathrm{mol} / \mathrm{L}$ 1,1',3,3'-tetraethoxypropane solutions were used as standard. MDA levels were presented as $\mu \mathrm{mol} / \mathrm{g}$ wet tissue.

AOPP were determined according to method described by Witko-Sarsat et al. ${ }^{20}$ AOPP were measured by spectrophotometrically and were calibrated with Cloramin-T solutions that in the presence of potassium iodide absorb at 340 $\mathrm{nm}$. In standard tubes, $50 \mu \mathrm{L}$ of $1.16 \mathrm{M}$ potassium iodide (KI) was added to $1000 \mu \mathrm{L}$ of chloramine-T solution $(0-100 \mathrm{mmol} /$ liter) followed by $100 \mu \mathrm{L}$ of acetic acid. In test tube, $1000 \mu \mathrm{L}$ of tissue homogenate diluted $1 / 5$ in PBS, $50 \mu \mathrm{L} 1.16 \mathrm{M} \mathrm{KI}$ and 100 $\mu \mathrm{L}$ of acetic acid were mixed and the absorbance of the reaction mixture is immediately read at $340 \mathrm{~nm}$ on the spectrophotometer against blank containing $1000 \mu \mathrm{L}$ PBS, $100 \mu \mathrm{L}$ acetic acid and 50 $\mu \mathrm{L} 1.16 \mathrm{M} \mathrm{KI}$.

Plasma was extracted with ethanol-ether $(3 / 1, \mathrm{v} / \mathrm{v})$ and was measured by spectrofluorometer at wavelength 360/430 (excitation/emission wavelength). Fluorescence was determined as relative fluorescent intensity (FI) units per milliliter $(\mathrm{FI} / \mathrm{ml})$ of plasma $^{21}$.

Data analysis was performed using the Statistical Package for Social Sciences (SPSS) version 15.0 for Windows (SPSS Inc, Chicago, IL). All variables were normally distributed about the mean. Data were presented as mean \pm SD. Differences between the groups were evaluated by One-Way analysis of variance (ANOVA) or Kruskal-Wallis variance analysis, whichever was appropriate. When the $\mathrm{p}$ values from the variance analysis were statistically significant, the Tukey honestly significant difference (HSD) or Mann-Whitney U multiple comparison test was used to determine which group was different from the others. A value of $\mathrm{p}<0.05$ was considered to be statistically significant. 


\section{Results}

The mean histopathological scores of the groups are given in Table 2 . When statistical analyses of the histopathological scores were performed, it was found that congestion and necrosis scores in the enoxaparin-treated group were significantly lower than the scores in the control group ( $\mathrm{p}<0.05$ for both parameters). The congestion and necrosis scores of the sham group were also significantly lower than those of the control group $(\mathrm{p}<0.05$ for both scores). There was no significant difference between the necrosis scores of the sham and enoxaparin groups ( $p>0.05)$, but the congestion scores of the enoxaparin group were higher than those of the sham group $(\mathrm{p}<0.05)$. No vacuolization was detected in any group (mean vacuolization score was 0.00 for all groups).

TABLE 2 - The mean pathological scores of the groups.

\begin{tabular}{cccc}
\hline GROUPS & $\begin{array}{c}\text { CONGES- } \\
\text { TION }\end{array}$ & $\begin{array}{c}\text { NECRO- } \\
\text { SIS }\end{array}$ & $\begin{array}{c}\text { VACUOLIZA- } \\
\text { TION }\end{array}$ \\
\hline SHAM & $0.25 \pm 0.12$ & $0.00 \pm 0.00$ & $0.00 \pm 0.00$ \\
CONTROL & $2.75 \pm 0.45^{\mathrm{a}, \mathrm{c}}$ & $1.83 \pm 0.71^{\mathrm{a}, \mathrm{c}}$ & $0.00 \pm 0.00$ \\
ENOXAPARIN & $1.64 \pm 0.49^{\mathrm{b}}$ & $0.42 \pm 0.19$ & $0.00 \pm 0.00$ \\
\hline
\end{tabular}

${ }^{a}$ significantly different, $\mathrm{p}<0.05$, sham $v s$ control; ${ }^{b}$ significantly different, $\mathrm{p}<0.05$, sham $v s$ enoxaparin, ${ }^{c}$ significantly different, $\mathrm{p}<0.05$, control $v s$ enoxaparin,

The histopathological findings are presented in Figures 1-3. Liver tissue sections from the sham group exhibited almost normal morphology. The portal areas and lobuli were regular and there was minimal inflammation or sinusoidal congestion. Pneumoperitoneum caused marked inflammatory cell infiltration, hepatocyte necrosis and sinusoidal congestion. Treatment with enoxaparin decreased the histopathological abnormalities when compared with the control group. Sparse mononuclear inflammatory cell infiltration and mild sinusoidal congestion were found in the liver specimens of the enoxaparin group.
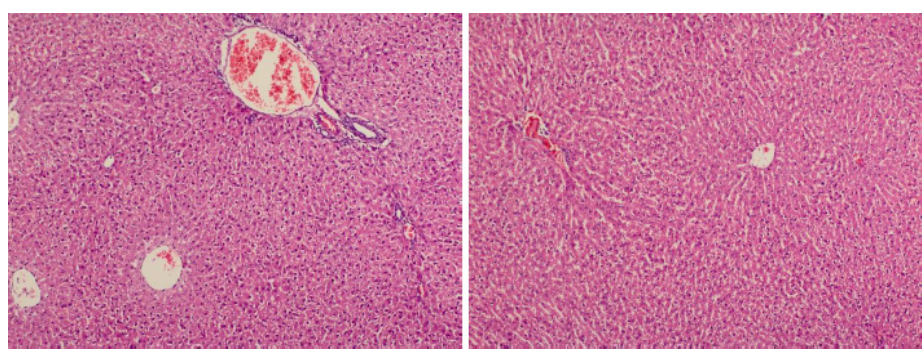

FÍGURE 1 - Sham group- Portal areas and lobuli are regular in form, there is no inflammation or sinusoidal congestion (x100, H\&E).

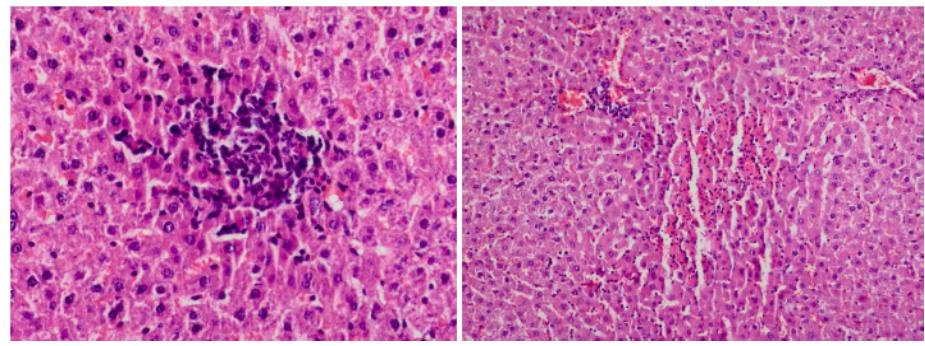

FIGURE 2 - Control group (only pneumoperitoneum with no treatmentgroup 2)-Mononuclear cell infiltration, necrosis and sinusoidal congestion in the liver tissue around the central vein were more intensive than in the group treated with enoxaparin (Group 3) (x400, x200, H\&E).

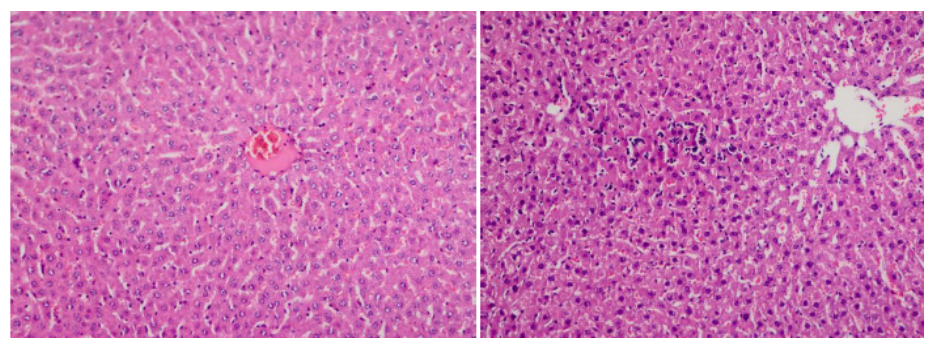

FÍGURE 3 - Sparse mononuclear cell infiltration and mild sinusoidal congestion in the enoxaparin group (x200, H\&E).

The mean levels of the liver function tests (AST, ALT and ALP) are summarized in Table 3. There was no significant difference in ALP levels between the groups ( $p>0.05)$. The highest tissue ALP levels were detected in the control group. The levels in the enoxaparin group were lower than those of the control group, but this difference was not statistically significant ( $\mathrm{p}>0.05)$.

The differences between the sham and other groups were significant for ALT and AST levels $(\mathrm{p}<0.05)$. The highest AST and ALT values were found in the control group. The use of enoxaparin decreased these levels, but the difference between the control and enoxaparin groups was not statistically significant $(p>0.05)$.

TABLE 3 - The mean ALT, AST, and ALP levels of the groups.

\begin{tabular}{cccc}
\hline GROUPS & AST & ALT & ALP \\
\hline SHAM & $103.37 \pm 23.14$ & $57.37 \pm 12.24$ & $193.42 \pm 60.55$ \\
CONTROL & $210.08 \pm 99.59^{\mathrm{a}}$ & $97.92 \pm 44.21^{\mathrm{a}}$ & $251.28 \pm 99.28$ \\
ENOXAPA- & $165.57 \pm 77.83^{\mathrm{b}}$ & $73.00 \pm 15.49^{\mathrm{b}}$ & $223.37 \pm 56.71$ \\
RIN & & & \\
\hline
\end{tabular}

${ }^{a}$ significantly different, $\mathrm{p}<0.05$, sham $v$ s control; ${ }^{b}$ significantly different, $\mathrm{p}<0.05$, sham vs enoxaparin.

The mean levels of the oxidative stress parameters for the liver (MDA, AOPP and TFOP) are summarized in Table 4. For MDA, AOPP, and TFOP levels, the differences between the sham 
and other groups were significant $(\mathrm{p}<0.05$ for all parameters). The highest MDA, AOPP, and TFOP values were found in the control group. The use of enoxaparin decreased the levels of all oxidative stress parameters, but the difference between the control and enoxaparin groups was not statistically significant $(p>0.05$ for all parameters).

TABLE 4 - The mean levels of the oxidative stress parameters.

\begin{tabular}{cccc}
\hline GROUPS & MDA & AOPP & DFOA \\
\hline SHAM & $39.82 \pm 14.33$ & $871.67 \pm 229.43$ & $97.61 \pm 17.21$ \\
CONTROL & $73.40 \pm 42.07^{\mathrm{a}}$ & $1472.55 \pm 388.09^{\mathrm{a}}$ & $142.97 \pm 31.10^{\mathrm{a}}$ \\
ENOXA- & $64.53 \pm 26.09^{\mathrm{b}}$ & $1343.73 \pm 313.68^{\mathrm{b}}$ & $134.06 \pm 39.02^{\mathrm{b}}$ \\
PARIN & & & \\
\hline
\end{tabular}

${ }^{a}$ significantly different, $\mathrm{p}<0.05$, sham $v s$ control; ${ }^{b}$ significantly different, $\mathrm{p}<0.05$, sham $v s$ enoxaparin.

\section{Discussion}

The impact of any surgical procedure on the human body can be described as surgical stress. As a result of surgical procedures, there may be a complex physiological stress response including the activation of inflammatory, metabolic, endocrine, and immunological mediators. In recent years, there has been increasing use of laparoscopic surgery for diagnostic and therapeutic purposes. A reduced requirement for analgesia, shorter hospital stay, decreased blood loss, less operative morbidity, and better cosmesis are just some of the patient-related benefits provided by this type of surgery. The smaller abdominal incisions and less tissue manipulation required by minimally invasive surgery result in less trauma and therefore, a lower stress response is expected. In the application of laparoscopic surgery, pneumoperitoneum is necessary for adequate visualization and operative manipulation. Several systems are affected by laparoscopic surgery and insufflation of $\mathrm{CO}_{2}$ into the peritoneal cavity, leading to changes in blood gases, acid-base balance, bacterial translocation, $\mathrm{CO} 2$ embolism, ischemia of various splanchnic organs, and cardiovascular, hepatic, renal, and respiratory physiology. Following insufflation and deflation of $\mathrm{CO}_{2}$, ischemia-reperfusion injury develops, thereby inducing oxidative stress ${ }^{22,23}$.

The level of intra-abdominal pressure may have an effect on the visceral organ injury. In a study by Komori et al. ${ }^{22}$, it was demonstrated that pneumoperitoneum at high pressure had a negative effect on postoperative liver regeneration but when the pressure was maintained at a low level, no adverse effects were observed. In all the parameters, there was no significant difference between the control and low-pressure groups. In the high pressure group, a significant decrease was determined in the rate of liver regeneration and mitotic count. In addition, hepatocellular damage, serum MDA and serum IL-6 were determined to be significantly higher in the high-pressure group compared with the control and/or low-pressure groups. It was concluded that the application of high-pressure pneumoperitoneum before $70 \%$ liver resection results in impaired postoperative liver regeneration.

Compared to unfractionated heparin (UFH), lowmolecular-weight heparin (LMWH) enoxaparin provides more stable anticoagulation, without any requirement for therapeutic monitoring. In the same way as UFH, Enoxaparin binds to and potentiates antithrombin action, as an endogenous inhibitor of coagulation factors XIa, IXa, Xa and IIa. Through the inhibition of these serine proteases, the coagulation cascade is inhibited, thereby preventing blood clot formation ${ }^{24}$.

Beyond the anticoagulative effects, the anti-inflammatory activities of LMWHs have been shown in several studies ${ }^{5-11}$. These studies have demonstrated that enoxaparin could be effective for managing many inflammatory disorders including inflammatory reaction after pediatric cataract surgery ${ }^{5}$, ST-segment elevated myocardial infarction ${ }^{6}$, mast cell-mediated allergic inflammation ${ }^{7}$, allergic asthma ${ }^{8,9}$, and acute colitis ${ }^{11}$. Enoxaparin has also been shown to be effective against many hepatic disorders and has a well-established hepatoprotective effect ${ }^{12-17}$.

In a study by Kukner et $a l .{ }^{13}$ the beneficial effects of enoxaparin against necrosis and apoptosis were investigated in the early stage of $\mathrm{CCL}_{4}$-induced liver damage. Enoxaparin was determined to reduce necrosis, apoptosis, and the number of mast cells but no effect was observed on lipid droplets in hepatocytes.

Enoxaparin has been shown to have beneficial effects on fibrosis progression and regenerative activity in the cirrhosis model ${ }^{12}$. In a study by Lee et al. ${ }^{14}$ LMWH was seen to exert antifibrotic effects via the inhibition of the TGF-b/Smad pathway in addition to the elimination of the extracellular matrix. Enoxaparin has also shown positive effects on radiation-induced liver toxicity ${ }^{15}$, and experimental cholestatic liver injury ${ }^{16}$.

Taha et al. ${ }^{17}$ researched the role of heparin in hepatic ischemia/reperfusion (I/R) injury in rabbits treated with $100 \mathrm{U} / \mathrm{kg}$ heparin or saline solution. Lower increases were seen in the levels of AST, ALT, and LDH in the rabbits treated with heparin. In the histological examination of the liver tissue of rabbits undergoing $\mathrm{I} / \mathrm{R}$, evident lesions were observed in the central lobule with significant inflammatory infiltration. Treatment with heparin led to a significant reduction in the lesions caused by $\mathrm{I} / \mathrm{R}$. 
In a previous study by the current authors ${ }^{25}$, an evaluation was made of the effects of low dose enoxaparin on plasma MDA levels and liver function tests during laparoscopic cholecystectomy. At 20 mins after deflation, MDA levels were seen to have significantly increased in the control group compared with the enoxaparin group. A significant increase in plasma MDA concentrations compared to the initial levels was determined in the control group. It was concluded that a mini dose of enoxaparin prevented the MDA increase after laparoscopic cholecystectomy without causing any bleeding disorder while having no effect on serum ALT and AST elevations. In the current study, significant differences were seen between the sham and other groups in respect of the ALT and AST levels. The highest AST and ALT values were determined in the control group. While enoxaparin was determined to have decreased these levels, the difference between the control and enoxaparin groups was not statistically significant. No significant difference was found in the ALP levels between the groups. The highest tissue ALP levels were in the control group and although the levels in the enoxaparin group were lower than those of the control group, the difference was not statistically significant. The results obtained in the current study were similar to the results of our previous study ${ }^{25}$ except for the MDA levels. Although the use of enoxaparin decreased the MDA values, the differences between the control and enoxaparin groups were not statistically significant in the present study. This might be due to various factors such as the enoxaparin doses used in the studies, or the different responses of human and rat organisms. Thus, there is need for further detailed studies of the antioxidant effects of enoxaparin.

Since our previous study was conducted on humans, biopsies for determination of pathological changes and the effects of enoxaparin on these changes were not taken and only biochemical changes were evaluated. The current study was planned primarily for the detection of the histopathological injury to the liver tissue and the possible effects of enoxaparin on this injury. Liver tissue sections from the sham group were found to have almost normal morphology. The portal areas and lobuli were regular and there was minimal inflammation or sinusoidal congestion in this group. Pneumoperitoneum resulted in marked inflammatory cell infiltration, hepatocyte necrosis and sinusoidal congestion. Treatment with enoxaparin decreased the histopathological abnormalities caused by pneumoperitoneum. Sparse mononuclear inflammatory cell infiltration and mild sinusoidal congestion were found in the liver specimens of the enoxaparin group and the histopathological scores were significantly lower in the enoxaparin group when compared with the control group (pneumoperitoneum with no treatment group). No vacuolization was detected in any of the groups. This might be because of the short duration of the experimental process. These results indicated that enoxaparin reduced the harmful effects of pneumoperitoneum on the liver and this effect might be primarily due to its anti-inflammatory activity. The results of the current study were also in accordance with previous studies that have shown the beneficial hepatoprotective effects of enoxaparin on different hepatic disorders ${ }^{12-17}$.

There have been various studies that have investigated the biochemical alterations in laparoscopic operations and experimental pneumoperitoneum models. Changes in serum levels of ALT, AST, gamma-glutamyl-transferase (GGT), ALP, and lactate dehydrogenase (LDH) were evaluated by Guven et al. ${ }^{26}$ in patients that had undergone laparoscopic cholecystectomy compared to open cholecystectomy. In a comparison of pre and postoperative biochemical tests from blood samples taken preoperatively and at 24 hours postoperatively, liver enzyme levels were found to be significantly increased in the laparoscopic cholecystectomy group. Significant differences were also determined between the laparoscopic cholecystectomy and open cholecystectomy groups. The conclusion of that study was that these elevated enzyme levels could be attributed in the main to the negative effects of the pneumoperitoneum on hepatic blood flow.

In another study, using indocyanine green elimination tests (ICG-PDR), Eryilmaz et al. ${ }^{27}$ examined the effects on liver functions of insufflation at different pressures. Measurements of serum AST, ALT, and total bilirubin levels were taken preoperatively, and at postoperative 1 hour and 24 hours. The results showed that $14 \mathrm{mmHg}$ pressure pneumoperitoneum decreased blood flow to the liver and increased postoperative 1-hour serum AST and ALT levels. It was therefore suggested that $10 \mathrm{mmHg}$ pressure pneumoperitoneum is superior to $14 \mathrm{mmHg}$ in laparoscopic cholecystectomy.

In the present study, the differences between the sham and other groups were significant for ALT and AST levels $(\mathrm{p}<0.05)$. The highest AST and ALT values were found in the control group. The use of enoxaparin decreased these levels, but the difference between the control and enoxaparin groups was not statistically significant $(\mathrm{p}>0.05)$. Although the minimal changes of liver enzymes during laparoscopic procedures do not seem to be clinically important, care should be taken before deciding to perform laparoscopic operations in patients with liver diseases.

Free radicals are highly reactive molecules with unpaired electrons, and undertake significant biological functions, including redox signaling and antibacterial defence. In laparoscopic surgery, oxidative stress may develop with the effect of several factors 
including the level of intra-abdominal pressure, and the type, temperature and humidity of the gas ${ }^{1}$. Free radicals can react with lipids in the cell and mitochondrial membranes and consequently initiate lipid peroxidation. MDA, which is the end product of lipid peroxidation, is commonly used as a marker of oxidative activity ${ }^{28}$. Neutrophil-derived oxidants can change protein structure, resulting in denaturation, protein fragmentation, and at very high levels, protein cross-linking. AOPP measure highly oxidized protein levels and may be used as an in vivo marker of oxidant-mediated protein damage ${ }^{20}$. A sensitive measurement method of oxidation is the measurement of fluorescent oxidation products (FOP), as it has been reported to be 10-100 times more sensitive than the colorimetric thiobarbituric acid-reactive substances assay. Different conditions associated with systemic oxidative stress are known to significantly increase the levels of fluorescent oxidation products $^{21}$.

In the current study, the levels of MDA, AOPP, and TFOP were measured for the evaluation of oxidative status and the effects of enoxaparin on oxidative stress during high-pressure pneumoperitoneum. The differences between the sham and other groups were significant for all parameters $(p<0.05)$. The highest levels of oxidative stress parameters were found in the control group, in other words, high-pressure pneumoperitoneum increased the oxidative stress. Although the use of enoxaparin decreased these values, the differences between the control and enoxaparin groups were not statistically significant ( $p>0.05$ for all parameters). In the light of these results, it was concluded that enoxaparin had a partial antioxidant effect.

The beneficial effects of enoxaparin was thought to be primarily due to its anti-inflammatory effect, together with a partial antioxidant effect. Enoxaparin has been used widely preoperatively for the prevention of thromboembolism in surgical clinics all over the world.

\section{Conclusions}

Enoxaparin ameliorated the harmful effects of high pressure $\mathrm{CO}_{2}$ pneumoperitoneum on the liver. The use of enoxaparin in laparoscopic operations for its hepatoprotective effect might be recommended after prospective randomized clinical trials.

\section{References}

1. Arsalani-Zadeh R, Ullah S, Khan S, MacFie J. Oxidative stress in laparoscopic versus open abdominal surgery: a systematic review. J Surg Res. 2011 Jul;169:e59-68. PMID: 21492871.

2. Hasukić S. Postoperative changes in liver function tests: randomized comparison of low- and high-pressure laparoscopic cholecystectomy. Surg Endosc. 2005;19:1451-5. PMID: 16206003.

3. Nickkholgh A, Barro-Bejarano M, Liang R, Zorn M, Mehrabi A, Gebhard MM, Büchler MW, Gutt CN, Schemmer P. Signs of reperfusion injury following $\mathrm{CO} 2$ pneumoperitoneum: an in vivo microscopy study. Surg Endosc. 2008;22:122-8. PMID: 17483991.

4. Iqbal Z, Cohen M. Enoxaparin: a pharmacologic and clinical review. Expert Opin Pharmacother. 2011;12:1157-70. PMID: 21470072.

5. Rumelt S, Stolovich C, Segal ZI, Rehany U. Intraoperative enoxaparin minimizes inflammatory reaction after pediatric cataract surgery. Am J Ophthalmol. 2006;141:433-7. PMID: 16490487.

6. Nasiripour S, Gholami K, Mousavi S, Mohagheghi A, Radfar M, Abdollahi M, Khazaeipour Z, Mojtahedzadeh M. Comparison of the effects of enoxaparin and heparin on inflammatory biomarkers in patients with ST-segment elevated myocardial infarction: A prospective open label pilot clinical trial. Iran J Pharm Res. 2014;13:583-90. PMID: 25237354.

7. Baram D, Rashkovsky M, Hershkoviz R, Drucker I, Reshef T, BenShitrit S, Mekori YA. Inhibitory effects of low molecular weight heparin on mediator release by mast cells: preferential inhibition of cytokine production and mast cell-dependent cutaneous inflammation. Clin Exp Immunol. 1997;110:485-91. PMID: 9409655.

8. Shastri MD, Stewart N, Horne J, Zaidi ST, Sohal SS, Peterson GM, Korner H, Gueven N, Patel RP. Non-anticoagulant fractions of enoxaparin suppress inflammatory cytokine release from peripheral blood mononuclear cells of allergic asthmatic individuals. PLoS One. 2015;10(6):e0128803. PMID: 26046354.

9. Shastri MD, Stewart N, Horne J, Peterson GM, Gueven N, Sohal SS, Patel RP. In-vitro suppression of IL-6 and IL-8 release from human pulmonary epithelial cells by non-anticoagulant fraction of enoxaparin. PLoS One. 2015;10:e0126763. PMID: 25961885.

10. Grosskopf I, Shaish A, Ray A, Harats D, Kamari Y. Low molecular weight heparin-induced increase in chylomicron-remnants clearance, is associated with decreased plasma TNF- $\alpha$ level and increased hepatic lipase activity. Thromb Res. 2014;133:688-92. PMID: 24525311.

11. Lean QY, Eri RD, Randall-Demllo S, Sohal SS, Stewart N, Peterson GM, Gueven N, Patel RP. Orally administered enoxaparin ameliorates acute colitis by reducing macrophage-associated inflammatory responses. PLoS One. 2015;10:e 0134259. PMID: 26218284.

12. Assy N, Hussein O, Khalil A, Luder A, Szvalb S, Paizi M, Spira G. The beneficial effect of aspirin and enoxaparin on fibrosis progression and regenerative activity in a rat model of cirrhosis. Dig Dis Sci. 2007;52:1187-93. PMID: 17372820.

13. Kukner A, Tore F, Firat T, Terzi EH, Oner H, Balaban YH, Ozogul C. The preventive effect of low molecular weight heparin on $\mathrm{CCL}_{4}$-induced necrosis and apoptosis in rat liver. Ann Hepatol. 2010;9:445-54. PMID: 21057164.

14. Lee JH, Lee H, Joung YK, Jung KH, Choi JH, Lee DH, Park KD, Hong SS. The use of low molecular weight heparin-pluronic nanogels to impede liver fibrosis by inhibition the TGF- $\beta /$ Smad signaling pathway. Biomaterials. 2011;32:1438-45. PMID: 21074845.

15. Seidensticker M, Seidensticker R, Damm R, Mohnike K, Pech M, Sangro B, Hass P, Wust P, Kropf S, Gademann G, Ricke J. Prospective randomized trial of enoxaparin, pentoxifylline and ursodeoxycholic acid for prevention of radiation-induced liver toxicity. PLoS One. 2014;9:e112731. PMID: 25393877.

16. Abdel-Salam OM, Baiuomy AR, Ameen A, Hassan NS. A study of unfractionated and low molecular weight heparins in a model of cholestatic liver injury in the rat. Pharmacol Res. 2005;51:59-67. PMID: 15519536. 
17. Taha MO, Gonçalves PF, Vidigal RO, Sacchi GP, Pinheiro FG, Brandão LS, Feguri S, Moraes-Filho AM, Ghadie MM, Magalhães KG, Simões MJ, Tersariol IL, Monteiro HP, Oliveira-Júnior IS, Jurkiewicz A, Caricati-Neto A. Protective effects of heparin on hepatic ischemia and reperfusion lesions in rabbits. Transplant Proc. 2009;41:812-5. PMID: 19376359.

18. Suzuki S, Toledo-Peneyra LH, Rodriquez FJ, Cejalvo D. Neutrophil infiltration as an important factor in liver ischemia and reperfusion injury. Modulating effects of FK506 and cylosporine. Transplantation. 1993;55:1265-72. PMID: 7685932.

19. Wasowicz W, Nève J, Peretz A. Optimized steps in fluorometric determination of thiobarbituric acid-reactive substances in serum: importance of extraction $\mathrm{pH}$ and influence of sample preservation and storage. Clin Chem. 1993;39:2522-6. PMID: 8252725.

20. Witko-Sarsat V, Friedlander M, Nguyen Khoa T, Capeillère-Blandin C, Nguyen AT, Canteloup S, Dayer JM, Jungers P, Drüeke T, Descamps-Latscha B. Advanced oxidation protein and products as novel mediators of inflammation and monocyte activation in chronic renal failure. J Immunol. 1998;161:2524-32. PMID: 9725252.

21. Wu T, Willett WC, Rifai N, Rimm EB. Plasma fluorescent oxidation products as potential markers of oxidative stress for epidemiologic studies. Am J Epidemiol. 2007;166:552-60. PMID: 17615091.

22. Komori Y, Iwashita Y, Ohta M, Kawano Y, Inomata M, Kitano S. Effects of different pressure levels of $\mathrm{CO} 2$ pneumoperitoneum on liver regeneration after liver resection in a rat model. Surg Endosc. 2014;28:2466-73. PMID: 24619333.

23. Yiannakopoulou E, Nikiteas N, Perrea D, Tsigris C. Minimally invasive surgery and oxidative stress response: what have we learned from animal studies? Surg Laparosc Endosc Percutan Tech. 2013;23:25-8.PMID: 23386145.

24. Meneveau N. Safety evaluation of enoxaparin in currently approved indications. Expert Opin Drug Saf. 2009;8:745-54. PMID 19860536.

25. Cavusoglu T, Ozcan N, Ogus E, Ozcan A, Kaymak C, Sahin S, Yilmaz FM, Tezel S. Enoxaparin effect on malondialdehyde levels in laparoscopic cholecystectomy. J Invest Surg. 2011;24:211-6. PMID: 21867390.
26. Guven HE, Oral S. Liver enzyme alterations after laparoscopic cholecystectomy. J Gastrointestin Liver Dis. 2007;16:391-4. PMID: 18193120.

27. Eryilmaz HB, Memis D, Sezer A, Inal MT. The effects of different insufflation pressures on liver functions assessed with LiMON on patients undergoing laparoscopic cholecystectomy. Scientific World J. 2012;2012:172575. PMID: 22619616.

28. Cighetti G1, Duca L, Bortone L, Sala S, Nava I, Fiorelli G, Cappellini MD. Oxidative status and malondialdehyde in betathalassemia patients. Eur J Clin Invest. 2002;32(Suppl 1):55-60. PMID: 11886433

\section{Correspondence:}

Turgut Cavusoglu

SB Ankara Egitim ve Arastirma Hastanesi

Genel Cerrahi Klinigi, 06340, Ulucanlar

Ankara, Turkey

Phone: +90.312.5953424

turgutcavusoglu@gmail.com

Received: July 25, 2016

Review: Sep 26, 2016

Accepted: Oct 24, 2016

Conflict of interest: none

Financial source: none

${ }^{1}$ Research performed at Department of General Surgery, Ankara Education and Research Hospital, Turkey. 